\title{
Peertechz
}

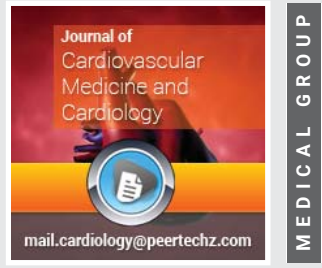

\section{Recurrent Tako-Tsubo Syndrome following repeated similar road traffic accidents}

\author{
Maeve Cahill ${ }^{1}$ and Gordon Pate ${ }^{2 *}$ \\ 1Physician Associate, The Galway Clinic, Doughiska, Galway, Ireland \\ ${ }^{2}$ Consultant Cardiologist, The Galway Clinic, Doughiska, Galway, Ireland
}

Received: 02 December, 2020

Accepted: 12 December, 2020

Published: 14 December, 2020

*Corresponding author: Dr. Gordon Pate, Consultant Cardiologist, The Galway Clinic, Doughiska, Galway, Ireland, Tel: 085-273-6646;

E-mail: gordon.pate@galwayclinic.com

Keywords: Recurrent tako-tsubo syndrome; Stress cardiomyopathy; Case report; Cardiac imaging

https://www.peertechz.com

\section{Abstract}

Tako-Tsubo Syndrome (TS) is a reversible cardiomyopathy that typically affects women with a history of anxiety, who have experienced a stressful event up to five days prior to presentation. We present the case of a woman who presented with recurring episodes of TS following two near-identical road traffic accidents, four years apart, including multiple imaging modalities.

\section{Introduction}

Tako-Tsubo Syndrome (TS) was first described thirty years ago by a Japanese scientist [1]. The name is derived from pots used in Japan to trap octopuses which resembles the apical ballooning seen on left ventriculogram in TS [2]. TS is a reversible cardiomyopathy that typically affects women with a history of anxiety, who have experienced a stressful event, either emotional or physical, up to five days prior to presentation [3]. TS is reported as accounting for $2 \%$ of patients presenting with clinical features of Acute Coronary Syndrome (ACS), and up to $10 \%$ if only female patients are considered [4]. Common emotional triggers include bereavement, arguments, fear etc. The most common physical triggers of TS include surgery, trauma and acute respiratory failure [5].

The exact pathophysiology of TS is unknown and several causes have been postulated. Up to $90 \%$ of patients diagnosed with TS are women aged between 65 and 70 years old [6]. TS most commonly affects post-menopausal women and there is thought to be a link between oestrogen levels and TS [7]. Oestrogen is cardio-protective and has vasodilatory effects, therefore decreased oestrogen levels can disrupt the coronary microcirculation and lead to sympathetic nervous system inhibition. Catecholamines, such as epinephrine and norepinephrine, are released during times of increased stress or anxiety. Catecholamine release in cardiac nerve endings and increased serum catecholamine levels have been observed in patients with TS. This is thought to contribute to apical ballooning by promoting epicardial and cardiac microvasculature vasospasm [8]. Overall the prognosis for TS is good, with almost $95 \%$ of patients recovering full cardiac function within a few weeks [9].

Recurrent TS is recognised but not common [10]. Here, we present the case of a woman who presented with recurring episodes of TS following two similar road traffic accidents, several years apart.

\section{Case presentation}

A 64-year-old woman, with no cardiac history, presented to the Acute Chest Pain Unit complaining of new onset chest discomfort. Four days prior to presentation, she was involved in a Road Traffic Accident (RTA) where her car was rearended with minimal damage. One hour after the incident, she described a central "knot-like" sensation in her chest similar to dyspepsia, with associated nausea and sweating. This episode lasted five hours and self-resolved. The next day, a similar episode occurred while driving. Following this, she noted exertional chest discomfort while walking at a slow pace on flat ground. These persisting symptoms prompted her to present to the Emergency Department. Other than anxiety, her past medical history included hypercholesterolemia but no other risk factors for cardiac disease. On presentation, she was visibly anxious but cardiovascular and respiratory examinations were unremarkable. She denied any trauma to 
the chest wall or tenderness. Initial ECG was normal with a modest rise in Troponin at $29 \mathrm{ng} / \mathrm{L}$. (normal 0-18 ng/L).

She was admitted and treated as a suspected acute coronary syndrome. The following day, troponin was within normal limits at $17 \mathrm{ng} / \mathrm{L}$ but she developed new inferolateral $\mathrm{T}$ wave inversion on ECG (Figure 1A). Coronary angiography did not show significant coronary artery disease (Figure $2 \mathrm{~A}+2 \mathrm{~B}$, Video $1+2$ ) but left ventriculogram demonstrated peri-apical ballooning, consistent with TS (Figure $2 \mathrm{C}+2 \mathrm{D}$, Video 3). Conservative treatment was implemented. She was discharged the following day on aspirin, bisoprolol, ramipril and rosuvastatin. At followup six months later, complete resolution was demonstrated on ECG (Figure 1B) and echocardiogram, as expected with TS.

Subsequently, four years later, she was involved in another RTA, a second rear-end collision where she was a front seat passenger. Thirty-minutes after the incident, she experienced exactly the same chest discomfort as four years previously. She presented directly to the Acute Chest Pain Unit. Cardiovascular examination was unremarkable; resting heart rate 50 . She was still on aspirin, bisoprolol, ramipril and rosuvastatin. Initial ECG showed T wave inversion in lead III, AVF, V6 and ST flattening in $\mathrm{V}_{4}-\mathrm{V} 5$, similar to her most recent follow-up ECG two years before. Initial troponin was again marginally raised at $73 \mathrm{ng} / \mathrm{L}$. Due to her history and the similar nature of the preceding events, a diagnosis of recurrent TS was suspected. An urgent echocardiogram was performed which showed the classical features of TS; peri-apical ballooning and ejection fraction of $30-35 \%$ (Figure 3, Video $4+5$ ). The following day there were new changes noted on her ECG including corrected QT interval prolongation, which was not drug- or electrolyteinduced, and marked widespread $\mathrm{T}$ wave inversion (Figure $1 \mathrm{C}$ ). Troponin levels rose to a maximum of $465 \mathrm{ng} / \mathrm{L}$. CT coronary angiogram did not show any significant obstructive disease (Figure 4). She was discharged on the same medications plus amlodipine and also diazepam as required. Six months later a cardiac MRI was normal with no myocardial thinning or scarring. (Figure 5, Video 8+9). A recent outpatient followup, a further three years on, confirmed good clinical recovery, unremarkable cardiac exam and normal echo (Video 6+7). There was some persistent $\mathrm{T}$ wave inversion inferiorly on her ECG. (Figure 1D). She reported short periods of anxiety in the interim, but no further traffic accidents!

\section{Discussion}

Recurrent TS is well described in the literature; but the particular features of this case, being related to recurrent RTAs, have not been described previously.

TS is most commonly seen in post-menopausal women, as in this case. Stressful triggers are classified into emotional and physical events in the literature. Patients with physical disorders (such as trauma, recent surgery or respiratory illness) are considered to have secondary TS, which is associated with higher mortality [11]. The study found that TS in patients with pre-existing anxiety is predominantly associated with emotional triggers. After an emotional stressful event, patients with anxiety can experience acute cardiac and vascular

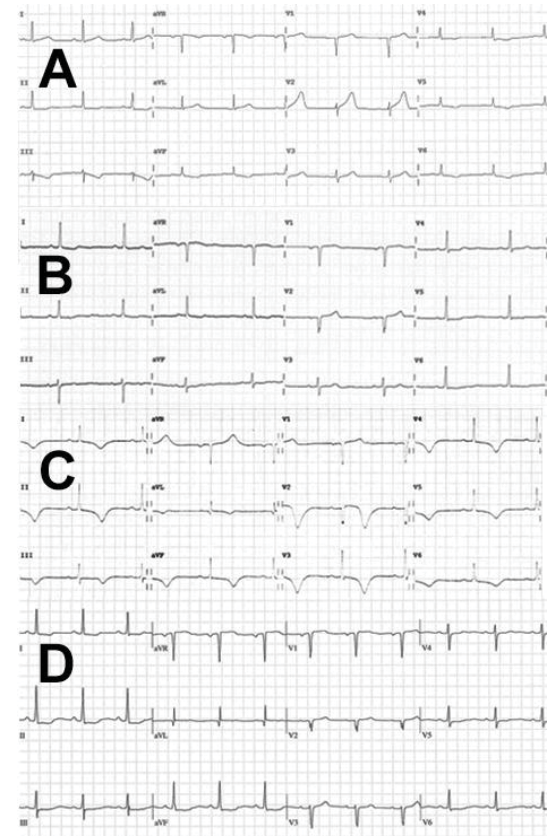

Figure 1: ECGs at various points in clinical course. A. During first presentation; showing infero-lateral T wave inversion. B. At six month follow-up; non-specific $T$ wave flattening. C. During second presentation four years later; gross widespread T wave inversion with QT prolongation. D. At follow-up seven years after initial episode; persistent mild infero-lateral ST depression.

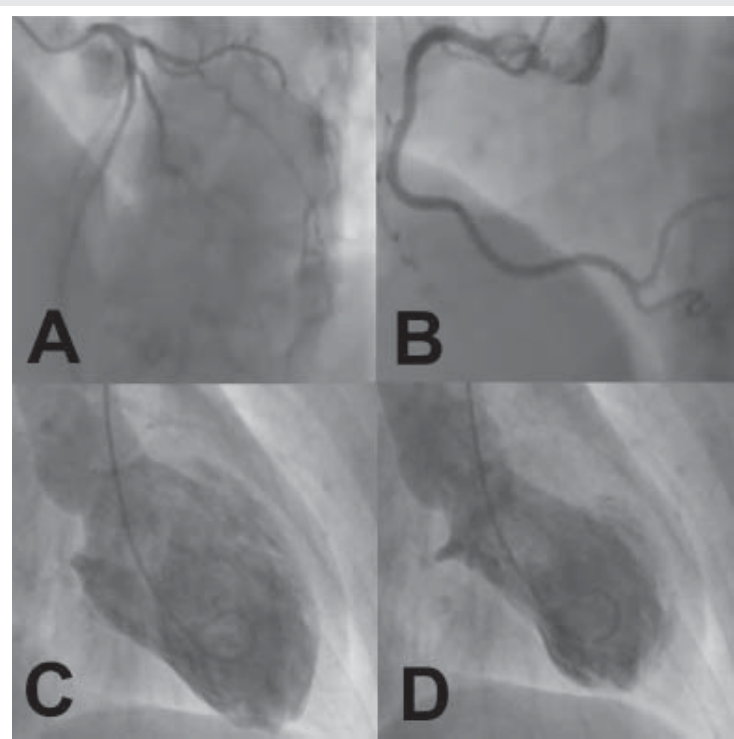

Figure 2: Coronary angiography at first presentation. A. Left coronary artery in LAO cranial. B Right coronary artery in LAO cranial. C. Left ventriculogram diastole. D. Left ventriculogram systole, demonstrating peri-apical ballooning.

sympathetic hyper-activation. This autonomic dysfunction can make patients more susceptible to TS [12]. The prevalence of anxiety disorders in patients with TS has been reported as between $26 \%$ to $56 \%$ of patients [13]. One study focused on the link between pre-existing anxiety, emotional triggers and TS. In this study, an RTA was categorised as a traumatic physical disorder [12]. The distinction between emotional and physical triggers can be difficult, as physical disorders may also cause emotional stress. In the case of our patient, the precipitating event may be considered an emotional trigger, as she did not sustain any significant injury from the impact. 


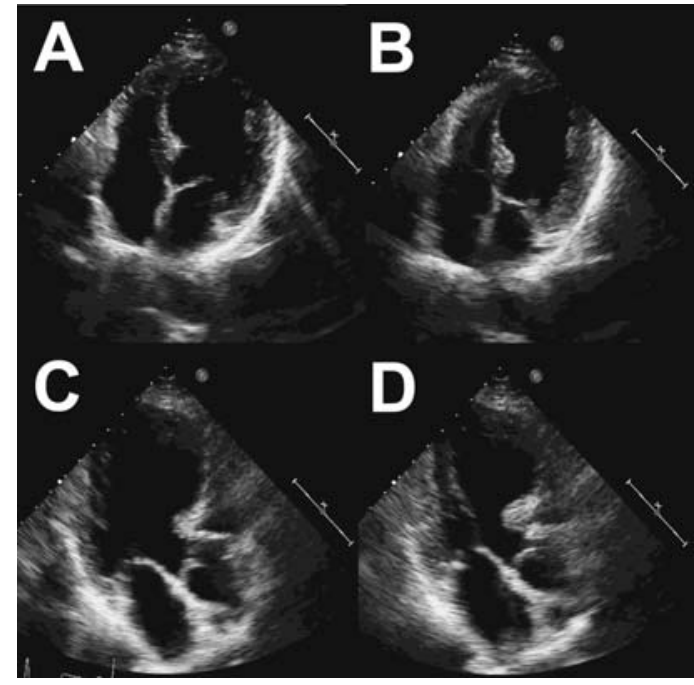

Figure 3: Echocardiogram at second presentation showing peri-apical ballooning. A. Parasternal short axis view - diastole. B. Parasternal short axis view - systole. C. Apical four chamber view - diastole. D. Apical four chamber view - systole.

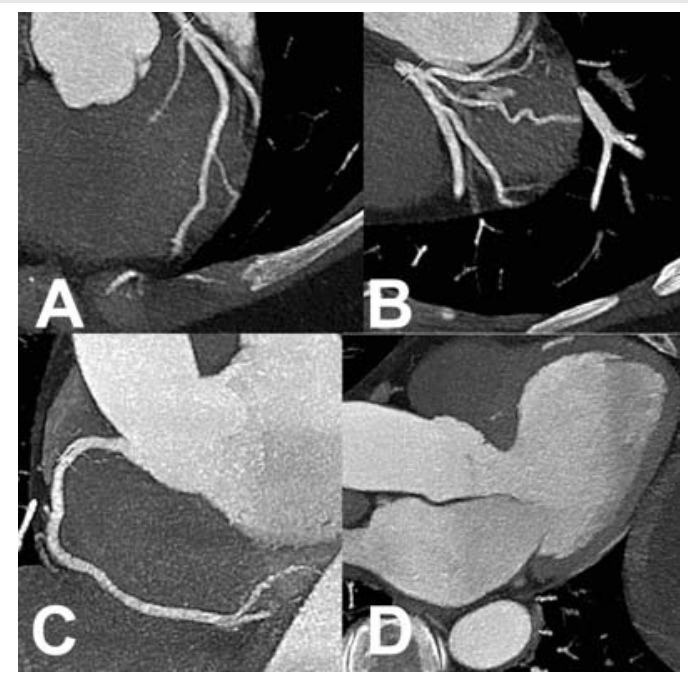

Figure 4: Computed tomography second presentation. A. Normal Left anterior descending artery. B. Normal Circumflex artery. C. Normal right coronary artery. D. Normal left ventriculogram in diastole; no scarring/thinning.

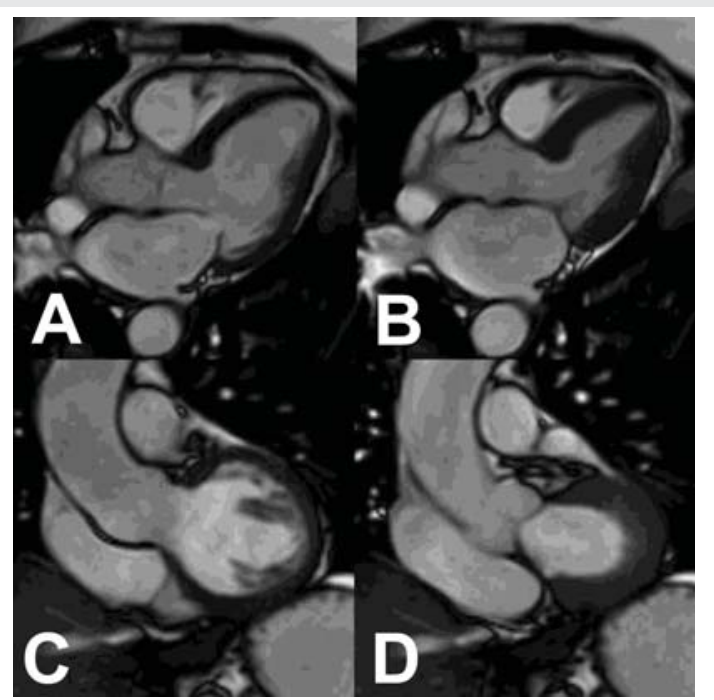

Figure 5: Cardiac MRI, normal ventriculograms one month after second presentation. A. Transverse section - diastole. B. Transverse section - systole. C. Coronal section - diastole. D. Coronal section - systole.
Recurrence of TS is not uncommon, with recurrence in the German Italian Stress Cardiomyopathy Registry occurring in $4 \%$ of patients. Most commonly the events occur in the first five years from the initial episode, with a predominance on single recurrent events [10]. Predictors for TS recurrence were examined and an emotional trigger provided a higher likelihood of recurrence, compared to a physical trigger. Medications, such as ACE-Inhibitors (ACEI) and beta blockers, were found to potentially reduce recurrence rates - likely due to a reduction of sympathetic activity on the myocardium through the renin-angiotensin-aldosterone-system. A position statement from the Heart Failure Association of the European Society of Cardiology advocates the use of beta blockers to reduce the likelihood of recurrence [6]. Beta blockers have also been recommended for patients with persistent anxiety, which can contribute to the risk of recurrence [3]. However, our patient was compliant with both classes of medication from the first episode four years previous; and still experienced a recurrence of TS with a near identical clinical pattern.

Recurrent TS precipitated by a similar emotional trigger is a rare phenomenon. Current literature details isolated case reports on patients with similar precipitants. One report by Sharath Babu, et al. (2019) documenting a post-menopausal woman with recurrent TS whose initial precipitant was a family bereavement. Eight months later, while preparing for her daughters' wedding, she was subsequently diagnosed with recurrent TS. Her clinical course and imaging were similar at both presentations [14]. The prognosis for patients suffering a recurrence of TS is comparable to a single episode, with similar in-hospital and 30-day mortality [15]. This case is significant as, to our knowledge, there are no case reports in the literature of patients with recurrent TS due to an RTA; moreover an RTA with the same type of impact and an identical clinical course.

\section{Conclusion}

This case is the first description of recurrent TS due to repeated road traffic accidents; as it happened that both incidences involved rear-end collisions. As is common with TS, this female patient had a background of anxiety and was postmenopausal, but the second episode happened despite being on a beta-blocker and ACEI. Excellent images were obtained, and she made a complete recovery on both occasions.

\section{Acknowledgements}

The authors wish to acknowledge the assistance of Drs Declan Sheppard and Derek Lohan, Consultant radiologists in The Galway Clinic, for their help in preparations of images for this report.

\section{(Supplementary Materials)}

\section{References}

1. Sato H, Tateishi H, Uchida T (1990) Takotsubo-type cardiomyopathy due to multivessel spasm. In: Kodama K, Haze K, Hon M, editors. Clinical Aspect of Myocardial Injury: From Ischemia to Heart Failure. Tokyo, Japan: Kagakuhyouronsha 56-64.

2. Tsuchihashi K, Ueshima K, Uchida T, et al. (2001) Transient left ventricular 
apical ballooning without coronary artery stenosis: a novel heart syndrome mimicking acute myocardial infarction. J Am Coll Cardiol 38: 11-18. Link: https://bit.ly/3qZrh7A

3. De Chazal HM, Del Buono MG, Keyser-Marcus L (2018) Stress Cardiomyopathy Diagnosis and Treatment: JACC State-of-the-Art Review. J Am Coll Cardiol 72 1955-1971. Link: https://bit.ly/37YRZUT

4. Y-Hassan S, Tornvall P (2018) Epidemiology, pathogenesis, and management of Takotsubo syndrome. Clin Auton Res 28: 53-65. Link: https://bit.ly/37YS1ft

5. Glaveckaite $S$, Serpytis $P$, Pečiūraitè D, Puronaitè R, Valevičienè N (2016) Clinical Features and Three-year Outcomes of Takotsubo (Stress) Cardiomyopathy: Observational Data from one Centre. Hellenic J Cardiol 57: 428-434. Link: https://bit.ly/3qZroA2

6. Lyon AR, Bossone E, Schneider B, Sechtem U, Citro R, et al. (2016) Current state of knowledge on Takotsubo syndrome: A Position Statement from the Taskforce on Takotsubo Syndrome of the Heart Failure Association of the European Society of Cardiology. Eur J Heart Fail 18: 8-27. Link: https://bit.ly/2IFmCpR

7. Ueyama T, Hano T, Kasamatsu K, Yamamoto K, Tsuruo Y, et al. (2003) Estrogen Attenuates the Emotional Stress-induced Cardiac Responses in the Animal Model of Tako-Tsubo (Ampulla) Cardiomyopathy. J Cardiovasc Pharmacol 42: S117-S120. Link: https://bit.ly/3nbqa25

8. Pelliccia F, Kaski JC, Crea F, Camici PG (2017) Pathophysiology of Takotsubo Syndrome. Circulation 135: 2426-2441. Link: https://bit.ly/2JVP4o8
9. Boyd B, Solh T (2020) Takotsubo cardiomyopathy. Journal of the American Academy of Physician Assistants 33: 24-29. Link: https://bit.ly/3qZrlie

10. El-Battrawy I, Borggrefe M, Akin I (2019) Predictors of thromboembolic events in Takotsubo syndrome. Eur J Heart Fail 21: 1482-1482. Link: https://bit.ly/3oO2Bgr

11. Ghadri JR, Wittstein I, Prasad A, Sharkey S, Dote K, et al. (2018) Internationa Expert Consensus Document on Takotsubo Syndrome (Part II): Diagnostic Workup, Outcome, and Management. Eur Heart J 39: 2047-2062. Link: https://bit.ly/2KiHJyV

12. Lazzeroni $D$, Bini $M$, Castiglioni $P$, Moderato $L$, Ciracì $C$, et al. (2018) Anxiety disorders and stressful events in Takotsubo syndrome. Cardiol J 25: 495-500. Link: https://bit.ly/3mcmmfC

13. Zvonarev V (2019) Takotsubo Cardiomyopathy: Medical and Psychiatric Aspects. Role of Psychotropic Medications in the Treatment of Adults with "Broken Heart" Syndrome. Cureus 11: e5177. Link: https://bit.ly/37aCUAA

14. Sharath Babu NM, Chacko ST, Chacko BR, Irodi A (2019) Recurrent Takotsubo cardiomyopathy in a postmenopausal Indian lady: Is there a pattern? J Postgrad Med 65: 112-115. Link: https://bit.ly/3oHU1zG

15. El-Battrawy I, Ansari U, Behnes M, Hillenbrand D, Schramm K, et al. (2016) Clinical and echocardiographic analysis of patients suffering from recurrent takotsubo cardiomyopathy. J Geriatr Cardiol. 13: 888-893. Link: https://bit.ly/3gGvVT8 